\title{
Pengaruh Human Relations dan Lingkungan Kerja Terhadap Kinerja Karyawan Pada PT. Matahari Departemen Store Cabang WTC Serpong Tangerang
}

\author{
Liawati* \\ *Universitas Pamulang. Email ; dosen02579@unpam.ac.id
}

\section{ARTICLES INFORMATION}

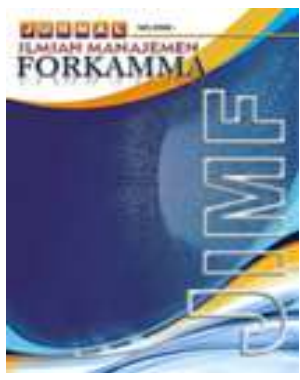

\section{JURNAL ILMIAH MANAJEMEN FORKAMMA}

Vol.3, No.3, Juli 2020

Halaman: $248-257$

(C) LPPM \& FORKAMMA

Prodi Magister Manajemen UNVERSITAS PAMULANG

ISSN (online) : 2599-171X ISSN (print) : :2598-9545

\section{Keyword :}

Human Relations, Work Environment, Employee Performance

JEL. classification : O15,

\section{Contact Author :}

PRODI

MAGISTER MANAJEMEN \& FORKAMMA UNPAM

JL.Surya Kencana No.1 Pamulang

Tangerang Selatan - Banten

Telp. (021) 7412566, Fax (021) 7412491 Email :

jurnalforkamma.unpam@gmail.com
Tujuan penelitian ini mengetahui pengaruh parsial dan simultan human relations dan lingkungan kerja terhadap kinerja karyawan pada PT. Matahari Departemen Store cabang WTC Serpong. Sampel yang digunakan 55 responden. Teknik analisis data dengan Regresi linier berganda. Hasil penelitian ini menunjukan bahwa. Semakin baik tingkat human relation antar karyawan, atasan dan pelanggan akan membuat peningkatan kinerja karyawan, pengaruh dari variabel tersebut adalah positif signifikan atau $(0,001<0,05)$. Semakin kondusif dan baik kondisi lingkungan kerja maka akan membuat peningkatan kinerja karyawan, pengaruh dari variabel tersebut adalah positif signifikan atau $(0,003<0,05)$. Meningkatnya human relations dan semakin baik lingkungan kerja bila dilakukan secara simultan akan membuat peningkatan kinerja karyawan, pengaruh dari kedua variabel tersebut adalah positif signifikan atau $(0,000<0,01)$.

The purpose of this study is to determine the partial and simultaneous influence of human relations and work environment on employee performance at PT. Matahari Department Store WTC Serpong branch. The sample used was 55 respondents. Data analysis techniques with multiple linear regression. The results of this study indicate that. The better the level of human relations between employees, superiors and customers will make an increase in employee performance. The effect of these variables is significantly positive or $(0.001$ $<0.05$ ). The more conducive and good working environment conditions will make employee performance improvement. The effect of these variables is significantly positive or $(0.003$ $<0.05)$. Increased human relations and a better working environment if done simultaneously will make an increase in employee performance. the effect of the two variables is significantly positive or $(0,000<0.01)$. 


\section{A. PENDAHULUAN}

Karyawan efektif dan cerdas dalam bekerja adalah harapan yang diinginkan oleh setiap pelaku bisnis. Untuk hal itu setiap karyawan akan berupaya mencapai tujuan untuk memaksimalkan kinerja dengan melakukan tugas sesuai dengan yang dipercayakan kepada atasan. Pekerja yang berkualitas umumnya akan merasa senang menghadapi setiap tantangan, mereka akan menjadikan tantangan tersebut sebagai suplemen tambahan untuk meningkatkan kreatifitas dalam bekerja.

Penelitian ini dilakukan pada PT. Matahari Department Store Cabang WTC Serpong berdasarkan hasil pengamatan penulis menemukan kinerja karywan masih belum optimal, seperti yang ditunjukkan oleh fakta bahwa masih ada karyawan yang tidak melakukan tugasnya secara optimal, yaitu, berbicara dengan rekan kerja lain selama jam kerja; pada saat memasuki area toko banyak karyawan yang terlambat. Serta adanya SPG yang tidak fokus dalam menjalankan tugasnya yang mengakibatkan keterampilan tenaga penjual dalam layanan pelanggan juga tidak optimal, misalnya keramahan dan kebaikan dalam layanan pelanggan masih kurang baik. Karena pekerja harus memperhatikan kebutuhan makhluk sosial, mereka akan termotivasi untuk melakukan tugas mereka sebaik mungkin, yang pada akhirnya dapat mengarah pada kekuatan dan efisiensi maksimum.

James (2014:124) mengemukakan "terdapat beberapa faktor yang mempengaruhi kinerja karyawan diantaranya faktor Kepemimpinan, Motivasi, Lingkungan Kerja, Kompensasi, Budaya Organisasi, Kepuasan Kerja, Kompetensi dan Disiplin Kerja".

"Human relation merupakan suatu hubungan yang terjalin antara seorang manajerdirektur perusahaan, kepala jawatan, atau pemimpin lembaga lainnya-dengan bawahannya terdapat struktur formal antara yang memimpin dan yang dipimpin", (Onong, 2002:51). "Dengan kegiatan human relation, para pemimpin organisasi berusaha memecahkan masalah-masalah dalam situasi kerja dan masalah-masalah yang menimpa bawahannya secara individual, sehingga dengan demikian dapat digairahkan kearah yang lebih efektif dalam upaya meningkatkan kinerja mereka", (Onong, 2002:58).

"Selain human relations, suatu organisasi juga perlu menciptakan lingkungan yang baik yaitu jika lingkungan kerja tersebut memiliki kondisi yang sehat, nyaman, aman serta menyenangkan bagi semua karyawan dalam upaya menyelesaikan tugasnya, lingkungan kerja di desain dengan sedemikian rupa agar tercipta hubungan kerja yang mengikat antara pekerja dengan lingkungannya". (Lewa, 2005:235).

Para karyawan pasti mengharapkan lingkungan kerja yang bisa membuat mereka merasa aman dan tenang dalam bekerja, akan tetapi jika lingkungan kerja penuh dengan ketidakharmonisan antar beberapa karyawan ataupun atasan, akan membuat timbulnya suatu permasalahan yang membuat kinerja karyawan menjadi menurun. Moekijat (2006), menyatakan "bahwa lingkungan kerja jelas mempengaruhi para karyawan perusahaan tersebut sehingga tempat kerja perlu diatur agar tidak mengganggu karyawan dalam melaksanakan pekerjaannya". 


\section{Rumusan Masalah}

a. Apakah human relations secara parsial mempengaruhi kinerja karyawan?

b. Apakah lingkungan kerja secara parsial mempengaruhi kinerja karyawan?

c. Apakah secara simultan human relations dan lingkungan kerja mempengaruhi kinerja karyawan?

\section{Tujuan Penelitian}

a. Untuk mengetahui pengaruh parsial human relations terhadap kinerja karyawan.

b. Untuk mengetahui pengaruh parsial llingkungan kerja terhadap kinerja karyawan.

c. Untuk mengetahui pengaruh simultan human relations dan lingkungan kerja terhadap kinerja karyawan.

\section{B. KAJIAN LITERATUR}

\section{Human Relations}

Menurut Hasibuan (2014:176) "Human relations merupakan hubungan yang harmonis, tercipta atas kesadaran dan kesediaan melebur keinginan individu demi terpadunya kepentingan bersama". Menurut Soleh Rosyad (2012:2) "Human relations merupakan syarat utama untuk keberhasilan suatu komunikasi baik komunikasi antar perorangan maupun komunikasi dalam organisasi instansi".

\section{Lingkungan Kerja}

Anorogo \& Widiyanti (2004:45) "Lingkungan kerja adalah segala sesuatu yang ada disekitar karyawan dan yang dapat mempengaruhi dirinya dalam menjalankan tugas - tugas yang dibebankannya". Menurut Mangkunegara (2013:68) "Lingkungan kerja adalah proses kerja dimana lingkungan saling berinteraksi menurut pola tertentu, dan masing-masing memiliki karakteristik atau nilai-nilai tertentu mengenai organisasi yang tidak akan lepas daripada lingkungan dimana organisasi itu berada, dan manusianya yang merupakan sentrum segalanya".

\section{Kinerja Karyawan}

Wirawan (2012:5), "Kinerja adalah keluaran yang dihasilkan oleh fungsi-fungsi atau indikatorindikator suatu pekerjaan atau suatu profesi dalam waktu tertentu". Sedangkan Anwar (2013:67) "Kinerja karyawan adalah hasil kerja secara kualitas dan kuantitas yang dicapai oleh seorang karyawan dalam melaksanakan tugasnya sesuai dengan tanggung jawab yang diberikan kepadanya". 


\section{Kerangka Berfikir}

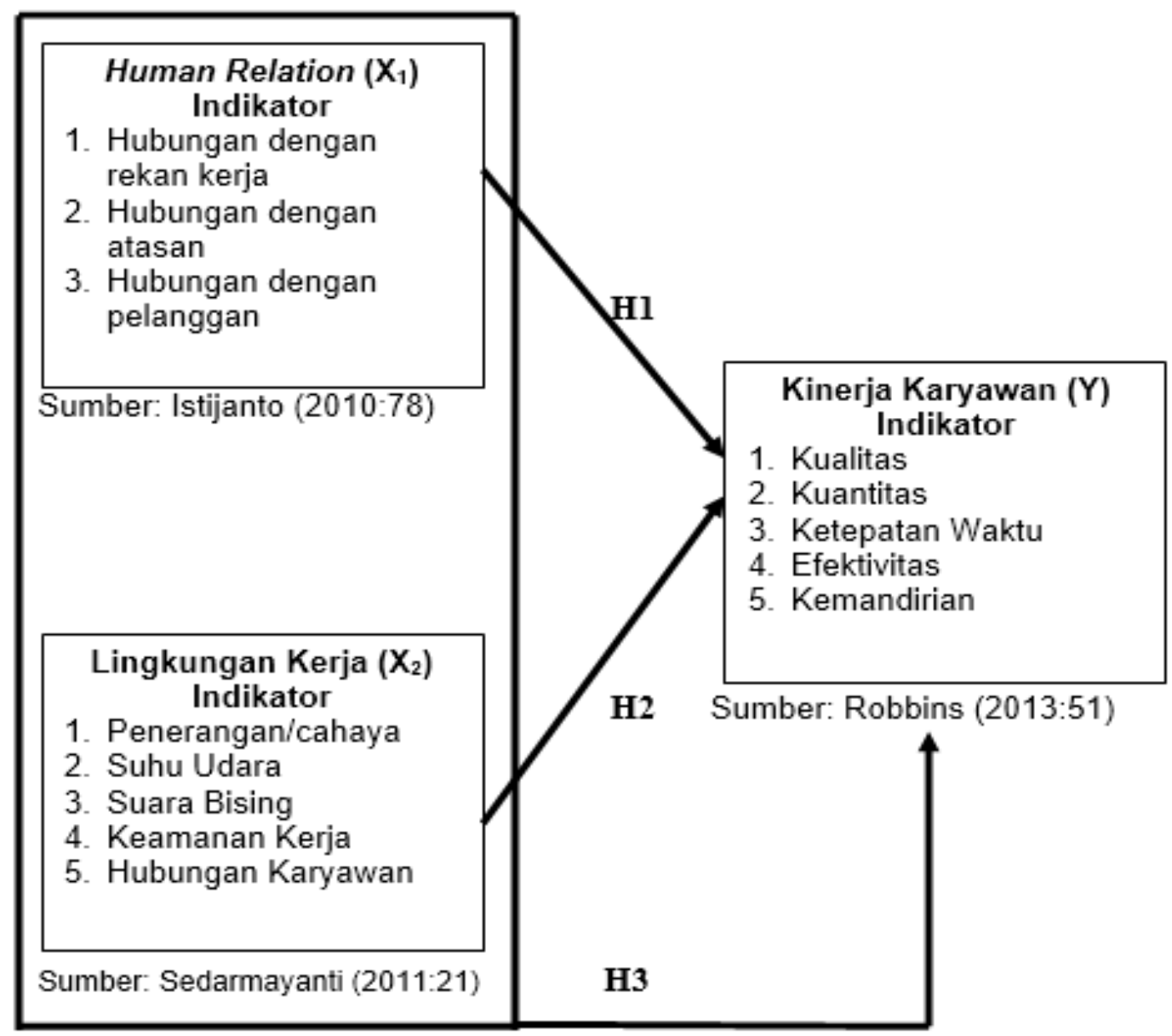

Gambar 1. Kerangka Berfikir

\section{METODOLOGI PENELITIAN}

Metode penelitian dengan Asosiatif metode, Sugiyono (2015:44) menjelaskan bahwa "penelitian Asosiatif bertujuan untuk mengetahui pengaruh atau hubungan antara dua variabel lebih". Populasinya seluruh karyawan PT. Matahari Departemen Store Cabang WTC Serpong Tangerang sebanyak 55 karyawan. "Dalam penelitian ini, teknik sampling yang digunakan yaitu sampling jenuh (sensus)”. (Sugiyono, 2015). Regrresi Linier Berganda digunakan sebagai analisis data. 


\section{HASIL DAN PEMBAHASAN}

Uji Instument

Uji Validitas dan Reliabilitas

Tabel 1. Hasil Uji Validitas

\begin{tabular}{|c|c|c|c|c|c|}
\hline Pernyataan & $\begin{array}{c}\text { Nilai rhitung } \\
\mathrm{X}_{1}\end{array}$ & $\begin{array}{c}\text { Nilai rhitung } \\
\mathrm{X}_{2}\end{array}$ & $\begin{array}{c}\text { Nilai } \text { ritung } \\
\mathrm{Y}\end{array}$ & $\begin{array}{c}\text { Nilai } \\
\text { rtabel }\end{array}$ & Keputusan \\
\hline P1 & 0,545 & 0,518 & 0,576 & 0,268 & Valid \\
\hline P2 & 0,667 & 0,560 & 0,455 & 0,268 & Valid \\
\hline P3 & 0,560 & 0,334 & 0,618 & 0,268 & Valid \\
\hline P4 & 0,665 & 0,696 & 0,580 & 0,268 & Valid \\
\hline P5 & 0,695 & 0,367 & 0,686 & 0,268 & Valid \\
\hline P6 & 0,281 & 0,483 & 0,379 & 0,268 & Valid \\
\hline P7 & 0,370 & 0,544 & 0,541 & 0,268 & Valid \\
\hline P8 & 0,403 & 0,691 & 0,497 & 0,268 & Valid \\
\hline P9 & 0,286 & 0,314 & 0,317 & 0,268 & Valid \\
\hline P10 & 0,532 & 0,432 & 0,537 & 0,268 & Valid \\
\hline
\end{tabular}

Sumber: Data diolah penulis (2020)

Dari 30 pernyataan disebar kepada karyawan terlihat bahwa seluruhnya memiliki nilai $r_{\text {hitung }}$ lebih tinggi dari $r_{\text {tabel }}(0,268)$ dengan semua item pernyataan valid.

Tabel 2 Hasil Uji Reliabilitas

\begin{tabular}{|c|c|c|c|}
\hline Variabel & $\begin{array}{c}\text { Nilai Cronbach } \\
\text { Alpha }\end{array}$ & Kriteria & Keputusan \\
\hline Human Relations $\left(\mathrm{X}_{1}\right)$ & 0,667 & $>0,60$ & Reliabel \\
\hline Lingkungan Keria $\left(\mathrm{X}_{2}\right)$ & 0,625 & $>0,60$ & Reliabel \\
\hline Kinerja karyawan $(\mathrm{Y})$ & 0,670 & $>0,60$ & Reliabel \\
\hline
\end{tabular}

Sumber: Data diolah penulis (2020) 
Tabel 2 diatas menunjukan kriteria sudah terpenuhi artinya 30 pernyataan yang disebar kepada karyawan adalah reliabel.

\section{Uji Asumsi Klasik}

\section{Uji Normalitas}

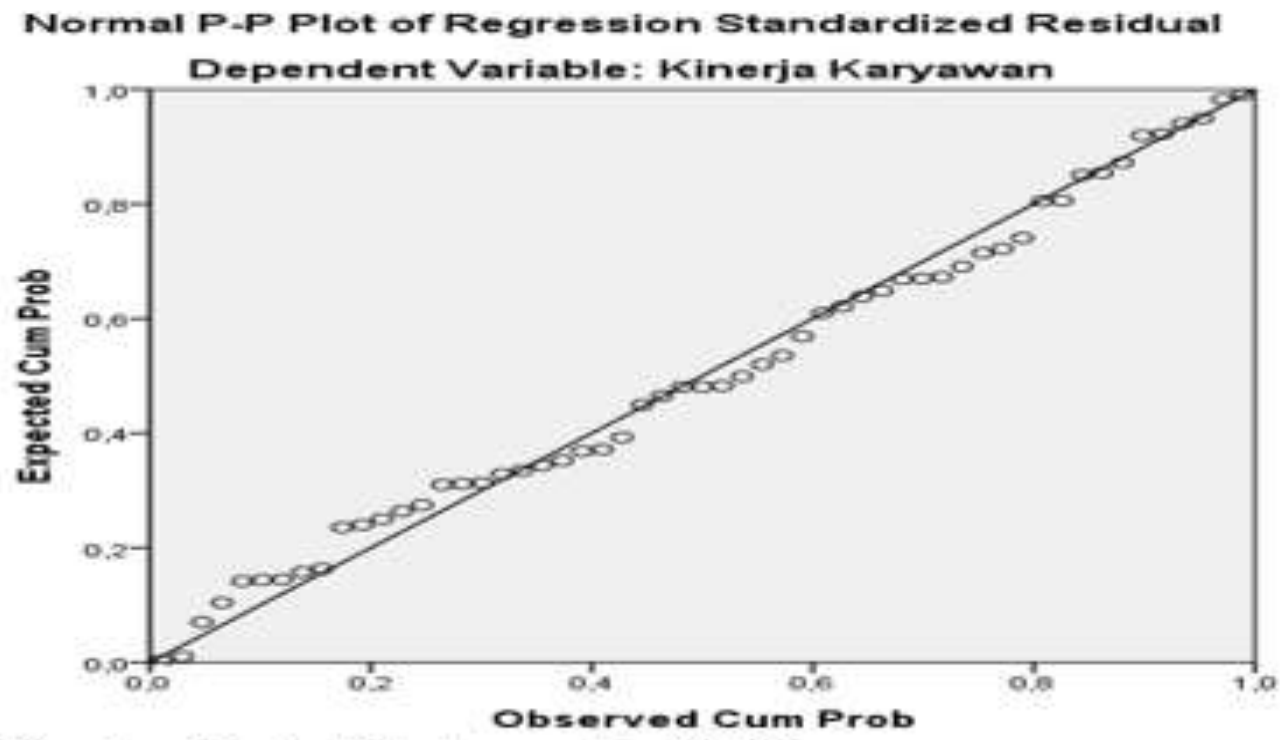

Sumber: Data diolah penulis (2020)

\section{Gambar 2. Hasil Uji Normalitas Data}

Penyebaran garis data terlihat pada Gambar 2 sudah mengikuti garis diagonal dan tidak ada yang melebar jauh, yang merupakan asumsi normalitas sudah dapat dipenuhi.

\section{Uji Multikolineritas}

\section{Tabel 3 Uji Multikolinearitas}

\begin{tabular}{|l|r|r|}
\hline \multirow{2}{*}{ Model } & \multicolumn{2}{|c|}{ Collinearity Statistics } \\
\cline { 2 - 3 } 1 (Constant) & Tolerance & \multicolumn{1}{c|}{ VIF } \\
Human Relations &, 902 & 1,109 \\
Lingkungan Kerja &, 902 & 1,109 \\
\hline
\end{tabular}

a. Dependent Variable: Kinerja Karyawan

Sumber: Data diolah penulis (2020) 
Pada tabel 3 menunjukan tidak terdapat adanya suatu gejala-gejala yang memungkinkan adanya multikolineritas karena VIF $<10$ dan toleransi $>0,10$.

\section{Uji Heteroskedastisitas}

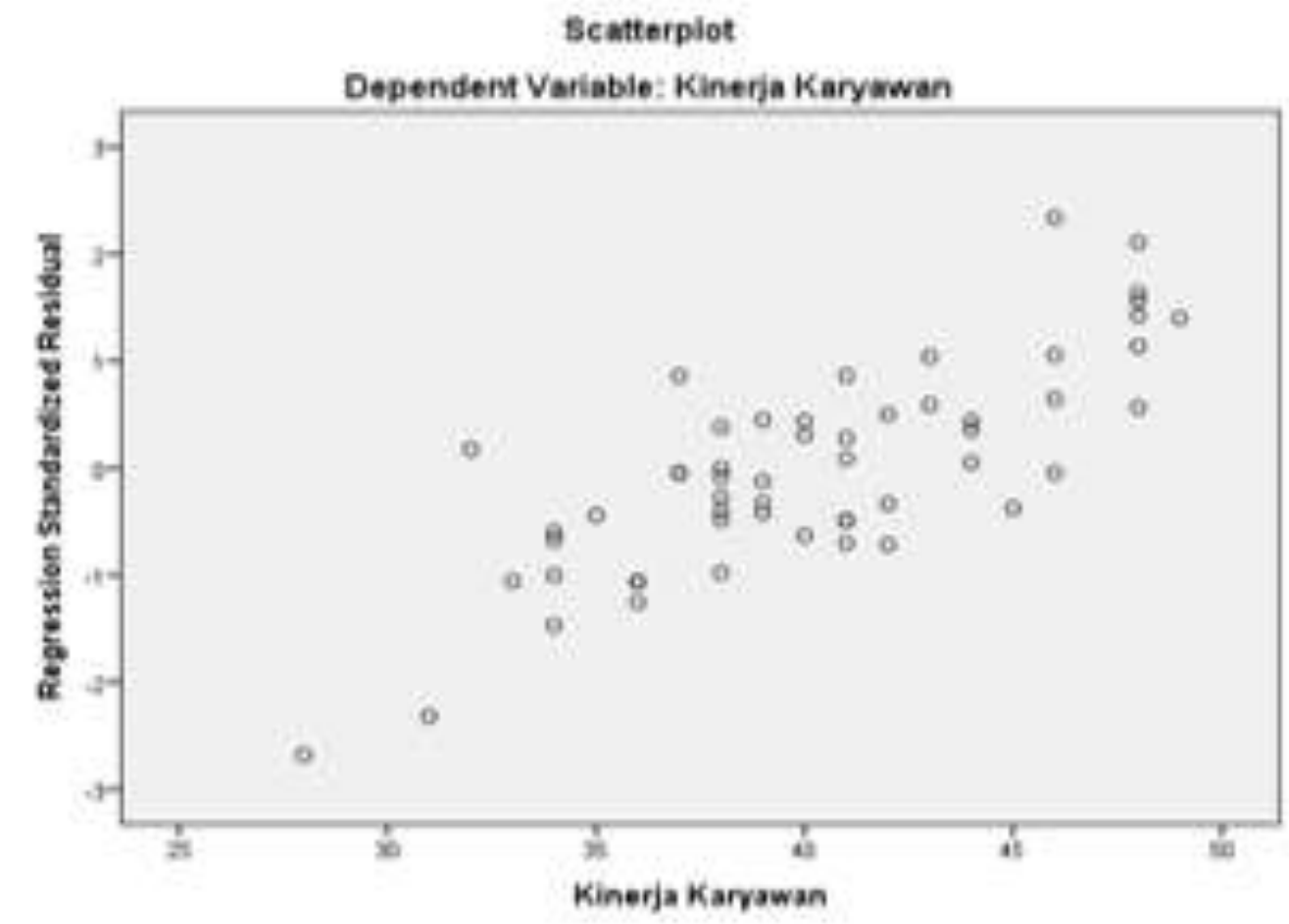

\section{Sumber : Data diolah Penulis (2020) Gambar 3. Hasil Uji Heteroskedastisitas}

"Dari grafik tersebut, dapat terlihat titik-titik yang menyebar secara acak, tidak membentuk suatu pola tertentu yang jelas, serta tersebar baik di atas maupun di bawah angka 0 (nol) pada sumbu Y, maka tidak terjadi heteroskedastisitas". 


\section{Uji Regresi Linier Berganda}

Tabel 4 Regresi Linier Berganda

\begin{tabular}{|c|c|c|c|c|c|}
\hline \multirow{2}{*}{ Model } & \multicolumn{2}{|c|}{$\begin{array}{l}\text { Unstandardized } \\
\text { Coefficients }\end{array}$} & \multirow{2}{*}{$\begin{array}{c}\begin{array}{c}\text { Standardize } \\
\text { d } \\
\text { Coefficients }\end{array} \\
\text { Beta }\end{array}$} & \multirow{2}{*}{$\mathrm{t}$} & \multirow{2}{*}{ Sig. } \\
\hline & B & $\begin{array}{c}\text { Std. } \\
\text { Error }\end{array}$ & & & \\
\hline 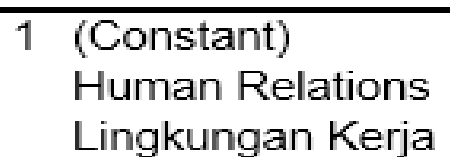 & $\begin{array}{r}9,927 \\
, 399 \\
379\end{array}$ & $\begin{array}{r}5,460 \\
, 118 \\
, 121\end{array}$ & $\begin{array}{l}, 392 \\
363\end{array}$ & $\begin{array}{l}1,818 \\
3,394 \\
3,145\end{array}$ & $\begin{array}{l}075 \\
001 \\
003\end{array}$ \\
\hline
\end{tabular}

a. Dependent Variable: Kinerja Karyawan

Sumber: Data diolah penulis (2020)

$$
\mathrm{Y}=9,927+0.399 \mathrm{X}_{1}+0.379 \mathrm{X}_{2}
$$

1. Nilai constant sebesar 9,927 artinya apabila human relations dan lingkungan kerja tidak mengalami peningkatan sama sekali, maka kinerja karyawan tetap 9,927.

2. Human relations memperoleh nilai regresi $0,399 X_{1}$ berarti bahwa pengaruh yang searah yang artinya jika human relations semakin baik antara atasan, sesama pegawai, dan pelanggan maka akan membuat peningkatan kinerja karyawan 0,399.

3. Lingkungan kerja memperoleh nilai regresi $0,379 \mathrm{X}_{2}$ yang berarti bahwa pengaruh yang searah pula yang artinya semakin kondusif dan harmonis kondisi lingkungan kerja kepada karyawan maka akan semakin membuat peningkatan kinerja karyawan 0,379.

\section{Uji Koefisien Determinasi}

Tabel 5. Koefisien Determinasi

\begin{tabular}{|c|c|c|c|c|}
\hline Model & $\mathrm{R}$ & $\begin{array}{c}\mathrm{R} \\
\text { Square }\end{array}$ & $\begin{array}{l}\text { Adjusted R } \\
\text { Square }\end{array}$ & $\begin{array}{l}\text { Std. Error of the } \\
\text { Estimate }\end{array}$ \\
\hline 1 & $612^{a}$ & 375 & 351 & 3,999 \\
\hline
\end{tabular}

a. Predictors: (Constant), Lingkungan Kerja, Human Relations

b. Dependent Variable: Kinerja Karyawan

Sumber: Data diolah penulis (2020)

Rsquare 0,375 atau juga 37,5\% adalah kontribusi dari human relations dan lingkungan kerja terhadap kinerja karyawan, sedangkan selebihnya $63,5 \%$ diakibatkan adanya konstruk lain yang tidak termasuk kedalam model ini.

\section{Uji Hipotesis Parsial}

JIMF (Jurnal IImiah Manajemen Forkamma), Vol.3, No.3, Juli 2020 
1. Hasil pengujian regresi pada tabel 4 angka angka sig $(0,001<0,05)$ menunjukan diterimanya $\mathrm{H}_{\mathrm{a} 1}$ dan ditolaknya $\mathrm{H}_{01}$ yang berarti bahwa human relations mempengaruhi kinerja karyawan secara parsial.

2. Hasil pengujian regresi pada tabel 4 angka angka sig $(0,003<0,05)$ menunjukan diterimanya $\mathrm{H}_{\mathrm{a} 2}$ dan ditolaknya $\mathrm{H}_{\mathrm{o} 2}$ yang berarti bahwa lingkungan kerja mempengaruhi kinerja karyawan secara parsial.

\section{Uji Hipotesis Simultan}

Tabel 6. Uji F hitung

\begin{tabular}{|l|r|r|r|r|l|}
\hline Model & \multicolumn{1}{|c|}{$\begin{array}{c}\text { Sum of } \\
\text { Squares }\end{array}$} & \multicolumn{1}{c|}{ df } & \multicolumn{1}{c|}{$\begin{array}{c}\text { Sean } \\
\text { Square }\end{array}$} & \multicolumn{1}{c|}{$\mathrm{F}$} & Siq. \\
\hline 1 Regression & 497,931 & 2 & 248,965 & 15,571 &, $000^{\mathrm{b}}$ \\
Residual & 831,451 & 52 & 15,989 & & \\
Total & 1329,382 & 54 & & & \\
\hline
\end{tabular}

a. Dependent Variable: Kinerja Karyawan

b. Predictors: (Constant), Lingkungan Kerja, Human Relations Sumber: Data diolah penulis (2020)

Angka pada probabilitas lebih kecil dan lebih rendah dari 0,01 atau $(0,000<0,01)$, yang berarti diterimanya $\mathrm{H}_{\mathrm{a} 3}$ dan ditolaknya $\mathrm{H}_{03}$ menunjukan kinerja karyawan dipengaruhi secara simultan oleh adanya variabel human relations dan lingkungan kerja.

\section{E. KESIMPULAN}

1. Semakin baik tingkat human relation antar karyawan, atasan dan pelanggan akan membuat peningkatan kinerja karyawan. Pengaruh dari variabel tersebut adalah positif signifikan atau $(0,001<0,05)$.

2. Semakin kondusif dan baik kondisi lingkungan kerja maka akan membuat peningkatan pada kinerja karyawan. Pengaruh dari variabel tersebut adalah positif signifikan atau $(0,003<$ 0,05).

3. Meningkatnya human relations dan semakin baik lingkungan kerja bila dilakukan secara simultan akan membuat peningkatan kinerja karyawan. Dari hasil uji F Pengaruh dari kedua variabel tersebut adalah positif signifikan atau $(0,000<0,01)$. 


\section{DAFTAR PUSTAKA}

Anoraga, P. dan Widiyanti, N. (2004). "Psikologi dalam Perusahaan”. Jakarta: Rineka Cipta.

Effendy, O. U. (2002), "Human Relation dan Public Relation”, Bandung: Mandar Maju.

Gibson, J. L., et all. (2014). "Perilaku Organisasi (Organizational. Behavior) (Edisi-9)". Jakarta: Erlangga.

Istijanto. (2010). "Riset Sumber Daya Manusia Edisi Revisi”. Jakarta: PT. Gramedia Pustaka Utama.

Kadim, A., Sunardi, N., \& Husain, T. (2020). The modeling firm's value based on financial ratios, intellectual capital and dividend policy. Accounting, 6(5), 859-870.

Lewa. S, (2005), "Perilaku dan Budaya Organisasi”, Bandung: PT Refika Aditama.

Malayu. H. (2014). "Manajemen Sumber Daya Manusia”. Jakarta: Bumi. Aksara.

Mangkunegara, A. P. (2013), "Manajemen Sumber Daya Manusia". Perusahaan, Remaja Rosdakarya, Bandung.

Robbins. S. P. (2013). "Perilaku Organisasi”. Jakarta: Salemba Empat.

Rosyad. S. (2012), "Manajemen Dakwah Islam”. Jakarta: Bulan Bintang.

Lesmana, R. (2017). Pengaruh Citra Perusahaan Terhadap Keputusan Pembelian Konsumen PT. Garuda Indonesia Tbk.(Persero). JIMF (Jurnal IImiah Manajemen Forkamma), 1(1).

Sedarmayanti. (2011). "Manajemen Sumber Daya Manusia, Reformasi Birokrasi dan. Manajemen Pegawai Negeri Sipil (cetakan kelima)", Bandung: CV. Mandar. Maju.

Sunardi, N., \& Lesmana, R. (2020). Pelaksanaan Alokasi Dana Desa Terhadap Manajemen Keuangan Desa dalam Meningkatkan Efektivitas Program Desa Sejahtera Mandiri Di Desa Cihambulu, Kec. Pabuaran, Kab. Subang. Jurnal SEKURITAS (Saham, Ekonomi, Keuangan dan Investasi), 3(3), 277-288.

Sugiyono (2015). "Metode Penelitian Kombinasi (Mix Methods)". Bandung: Alfabeta.

Wirawan. (2012). "Evaluasi: Teori, Model, Standar, Aplikasi, dan Profesi”. Depok. PT Raja Grafindo Persada. 